Annals of Glaciology 61985

(C) International Glaciological Society

\title{
SENSING OF SNOWPACK MELTING BY AN ACTIVE MICROWAVE SYSTEM WITH FIXED FREQUENCY
}

\author{
by
}

Masahiro Suzuki, Tadashi Matsumoto, Daisuke Kuroiwa

Hokkaido Institute of Technology, 419-2, Teine-Maeda, Sapporo, Japan 061-24

Kazuo Fujino, Gorow Wakahama

Institute of Low Temperature Science, Hokkaido University, Sapporo, Japan 060

\begin{abstract}
Using continuous microwave systems at fixed frequencies in the $\mathrm{X}$ - and $\mathrm{R}$-band, surface depression of a snowpack was obtained from interference between the emitted wave, at normal incidence to the snowpack surface, and the reflected wave from the snow surface. The microwave system worked as a simple interferometer in air with respect to the snow surface. The values of the depression could be obtained from the numbers of cycles of the fluctuation and the wavelength of the microwave used.
\end{abstract}

\section{INTRODUCTION}

The application of microwave to remote sensing of snowpacks has received increasing attention because of its capability to penetrate the snowpack and respond to variation in its subsurface properties under all weather conditions (Ulaby 1982). The present authors have measured the interference between an emitted and a back-scattered wave, that is, reflection from the surface and diffused reflection from the subsurface layers within the snowpack, using fixed frequencies together with various parameters of the snowpack, and clarified the relation between the surface depression of the snowpack and the fluctuation of the interference signal.

\section{MICROWAVE EXPERIMENTAL APPARATUS}

Block diagrams of the experimental apparatus transmitting a X-band $(9.37 \mathrm{GHz})$ and $\mathrm{R}$-band $(31.5 \mathrm{GHz})$ frequencies, are shown in Figure $1(\mathrm{~A})$ and $1(\mathrm{~B})$.

It is clear from the figures that a continuous wave is emitted at normal incidence to the surface of snowpack. The back-scattered wave, that is, reflection from surface and diffused reflection from subsurface layers within the snowpack, is received by the same horn as is used for emission.

The received signal is separated from the emitted signal by the circulator and is guided toward the power meter through the thermistor mount. However, part of the emitted wave leaks toward the thermistor mount through the circulator and serves as a reference signal which interferes with the received signal. The power meter measures the actual power of this interference signal.

The intensity and phase of the received signal are a function of both the impedance of the snowpack and the distance between the horn and the surface of the snowpack. If these factors change with time, fluctuations of the power of the interference signal will be observed (Suzuki and others 1983).

As will be shown later, the time period of the fluctuation depends mainly on the rate of surface depression and the amplitude depends on the change of reflectivity of the snow surface.

\section{RESULTS OF LABORATORY EXPERIMENTS}

Using the systems mentioned above, many experiments were conducted in a laboratory investigating fine-grained rectangular snow slabs, $33 \times 42 \times 27 \mathrm{~cm}$, that were gradually melted at room temperature. The intensity of the

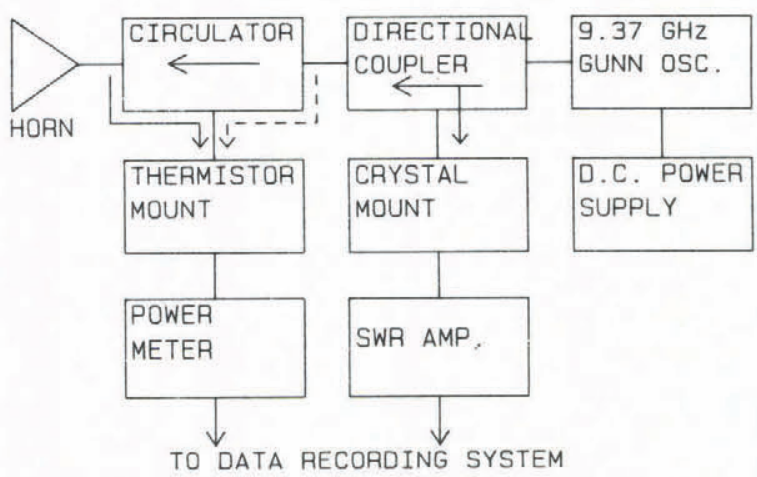

(A) X-BAND WAVEGUIDE SYSTEM

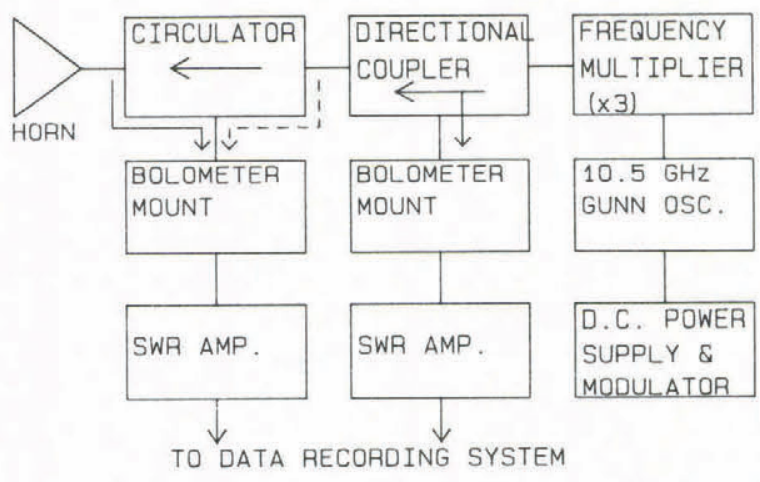

(B) R-BAND WAVEGUIDE SYSTEM

Fig.1. Block diagrams of experimental apparatus.

interference signal began to oscillate as the surface temperature of the snow slab rose to $0^{\circ} \mathrm{C}$.

In Figures 2 and 3, variations with time in intensity of the signals (X- and the R-band), the thickness of the snow slab, the room and the snow temperature are shown respectively.

It is clear from the figures that the time period of the fluctuation is proportional to the rate of decrease in snow thickness due to melting.

In Figure 2, the surface of the snow slab sank by approximately $32 \mathrm{~mm}$ during the time period from 1.25 to 7.5 hours, because of melting. The number of power maxima for this period is 2 ; the value of surface depression per cycle of oscillation comes to $16 \mathrm{~mm}$, equivalent to the half value of the wavelength of the microwave of $9.37 \mathrm{GHz}$ in frequency (that is, $16 \mathrm{~mm}$ ). In Figure 3, the difference of the snow thickness measured during $1.5-6$ hours is approximately $24 \mathrm{~mm}$ and the number of cycles of 

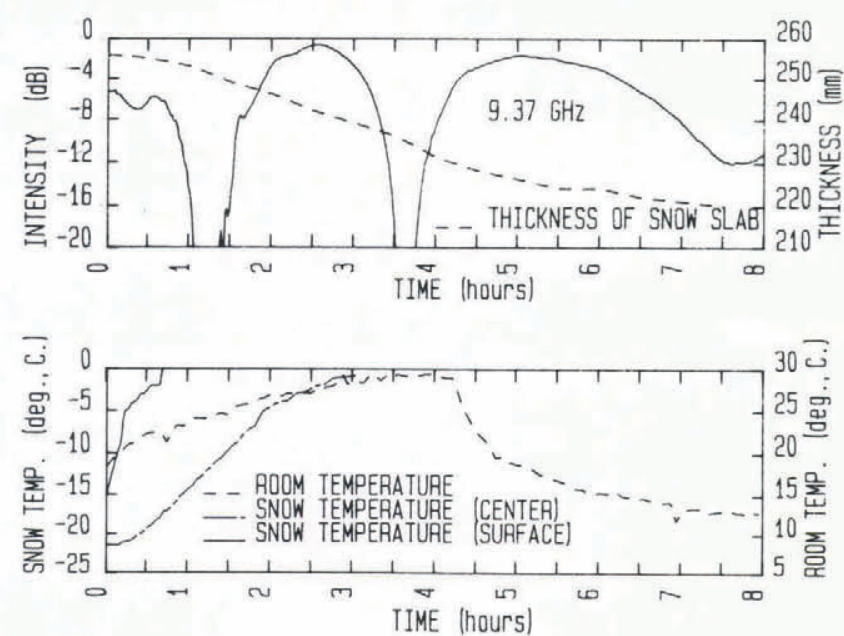

Fig.2. Results of laboratory experiment at the frquency of $9.37 \mathrm{GHz}$.
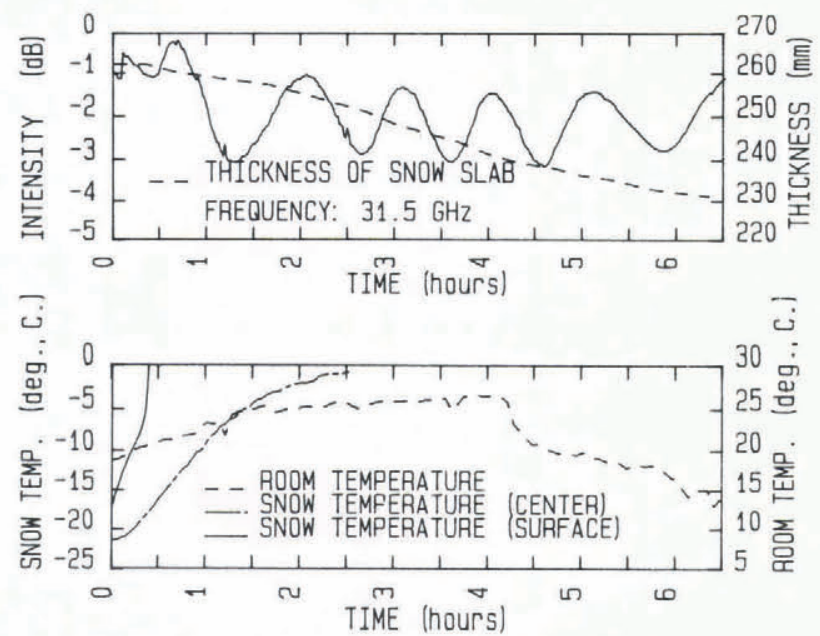

Fig.3. Results of laboratory experiment at the frequency of $31.5 \mathrm{GHz}$

oscillation can be found to be 4. Hence, the surface depression per cycle comes to $6 \mathrm{~mm}$. This value is roughly equivalent to one half of the wavelength at $31.5 \mathrm{GHz},(4.8$ $\mathrm{mm})$.

\section{SENSING OF A HOMOGENEOUS SNOW LAYER}

A field experiment was conducted at Mt Daisetsu National Park, Hokkaido, Japan, in 1982. The snowpack was about 3 metres in depth and composed of wet granular snow at a temperature of $0^{\circ} \mathrm{C}$ through the day and night. The weather was fine and calm during the field experiment.

Figure 4 shows the diurnal variation in intensity of the interference signals at $\mathrm{X}$-band and the $\mathrm{R}$-band frequencies, which were obtained from 20:30 8 May to $8: 30$ 11 May. As seen in this figure, the fluctuation in intensity of the signal is remarkable in both cases during the daytime, but becomes relatively settled at night. In the daytime, the period of fluctuation of the X-band signal is approximately three times that of the $\mathrm{R}$-band signal.

The number of cycles of oscillation in the diurnal variation from 4:30 9 May, to 8:30 11 May, of the former is 8 and that of the latter is 27. From the results of the laboratory experiments, we can estimate the surface depression. By multiplying the half wavelength by the number of cycles of oscillation in the diurnal variation in intensity of each microwave, we obtain the estimated surface depression, that is, $128 \mathrm{~mm}$ for the former, and $129.6 \mathrm{~mm}$ for the latter.

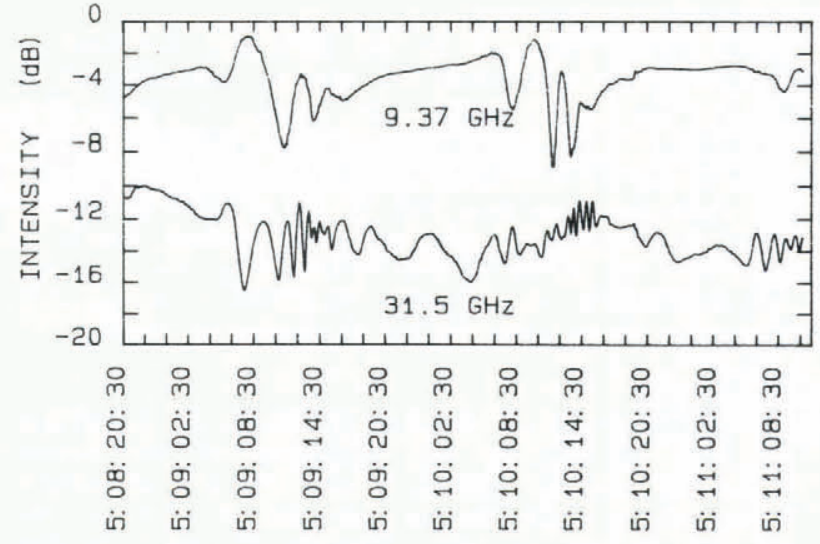

TIME (month: day: hour: minute)

Fig.4. Diurnal variations in intensity of the interference signal between an emitted and a back-scattered wave (Mt Daisetsu in 1982).

\section{SENSING OF AN UNHOMOGENEOUS SNOW LAYER}

This field experiment was carried out at Toikanbetsu Forest of Hokkaido in 1983. During the experiment, the weather was fine, with a gentle wind. Snow cover was 60 $\mathrm{cm}$ deep and composed of coarse granular snow, which contained several sheets of ice plates. The frequency of 9.37 $\mathrm{GHz}$ was selected as a fixed one for a microwave sensor. In order to measure the surface depression continuously, mechanical sensor was mounted on the snow surface.

Figure 5 shows the diurnal variation in intensity of the interference signal and the surface depression measured from 17:00, 29 March to 13:00, 1 April. From the variation

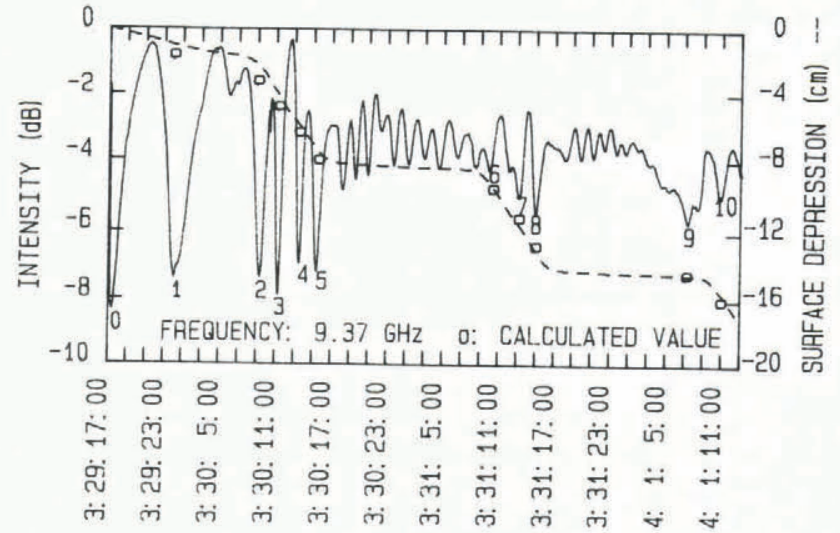

TIME (month: day: hour: minute)

Fig.5. Diurnal variations in relative intensity of the interference signal and the surface depression of a snowpack (Toikanbetsu in 1983).

in intensity of the signal in Figure 5 it is considered that the oscillations labelled under peaks, $0-10$, whose amplitudes are relatively large, are created mainly by the depression of the snow surface, and that the other oscillations whose amplitudes are relatively small are created mainly by a change of electrical thickness of the layer between the snow surface and the ice plate, due to drainage or freezing, because there was no remarkable surface depression as seen in the figure.

If the foregoing is valid, we can calculate the surface depression at each time interval from 1 to 10 . In Figure 5, ten plots denoted by "o" show calculated values of surface depression which were obtained by multiplying the half value of the wavelength of the microwave of $9.37 \mathrm{GHz}$ by the number of labels, $1-10$; these values are close to the curve of the surface depression measured with the mechanical sensor. 


\section{CONCLUDING REMARKS}

Our results obtained in the laboratory indicated a possibility for us to measure the surface depression of a snowpack due to melting by using a microwave interferometer. The amplitude of the oscillation in the intensity of the interference signal is considered to depend mainly upon the impedance, that is, the physical properties of snow such as density, grain size and wetness, but it is believed that the period of the fluctuation in the intensity of the interference wave depends significantly on the rate of depression of the snow surface as a result of melting.

\section{REFERENCES}

Suzuki M, Matsumoto T, Kuroiwa D, Fujino K, Wakahama G 1983 Research on the interaction of microwaves with snow and ice. Part I. A study on the microwave back-scattering from melting snowpack. Memoirs of the National Institute of Polar Research of Japan, Special issue 29: 166-175

Ulaby F T 1982 Radar signatures of terrain: useful monitors of renewable resources. Proceedings of IEEE 70: $1410-1428$ 